\title{
Pd overlayer on Oxygen pre-covered Graphene/Ru(0001): Thermal Stability
}

\author{
Cheol-Woo Yi ${ }^{\mathrm{a}, \mathrm{b}}$ and János Szanyi ${ }^{*} \mathrm{~b}$ \\ ${ }^{a}$ Department of Chemistry and Institute of Basic Science, Sungshin Women's University, Seoul \\ 136-742, South Korea \\ ${ }^{b}$ Institute for Integrated Catalysis, Pacific Northwest National Laboratory, P.O. Box 999, MSIN: \\ K8-87, Richland, WA, USA
}

\begin{abstract}
The behaviors of metal atoms on graphene and graphene oxide are quite important since the composite materials consisting of graphene and transition metal(s) can be employed in numerous technological applications. Despite that the great importance of metal particles on graphene or graphene oxide substrates, fundamental studies of the physical and chemical properties of metal clusters on graphene or graphene oxide are still needed. In this study, in order to elucidate the properties of metal on graphene (GR) and oxygen-precovered graphene (O-GR), the systems consisting of Pd deposited either on to pristine graphene or oxygen-precovered graphene layers have been investigated. The oxygen-precovered graphene was prepared by hot filament method under oxygen atmosphere. Exposure of the graphene layer to atomic oxygen resulted in both intercalation of oxygen between the graphene layer and the $\mathrm{Ru}(0001)$ substrate and functionalization of the graphene layer (mainly epoxide formation). Pd deposited onto the oxidized graphene layer interacted strongly with the intercalated oxygen, resulting in intercalation of some of the deposited Pd even at lower temperature than we have seen for Pd on pristine graphene. At the low coverage of 0.25 MLE, Pd mainly formed large planar domains (spreading of Pd on the oxidized graphene layer) and intercalated between the graphene layer and the $\mathrm{Ru}$ substrate at lower temperature due to the interaction between $\mathrm{Pd}$ and intercalated
\end{abstract}

\footnotetext{
*To whom correspondence should be addressed. E-mail: janos.szanyi@pnnl.gov 
oxygen. At higher temperatures, both systems experience the same phenomenon, i.e., the intercalation of all of palladium between the graphene layer and Ru substrate. The intercalated Pd desorbed from the substrate at temperatures $>1100 \mathrm{~K}$. At higher Pd coverages, some of the Pd intercalated between the GR and the Ru substrate, while small Pd particles spread on the surface. The structure of the Pd overlayer after the $800 \mathrm{~K}$ annealing cycle seems to be very different from that observed at $300 \mathrm{~K}$. The Pd that was present in small clusters spread out on the graphene surface due to the interaction with the intercalated Pd layer through the graphene layer. This interaction stabilized the Pd and even after $1000 \mathrm{~K}$ annealing the metal film was stable. After even higher temperature annealing all the Pd intercalated, and then desorbed above $1100 \mathrm{~K}$. The graphene layer preserved its perfect structure (i.e., continuity) without any damage after the intercalation and desorption of Pd. 


\section{Introduction}

Graphene is a two-dimensional single atomic layer with a honeycomb structure

consisting of $\mathrm{sp}^{2}$-hybridized carbon. It is recently applied in many fields [1], such as mechanical, electrical, and optical materials, due to its remarkable electronics properties. Composite materials consisting of graphene and transition metal(s) are attracting a great attention for numerous technological applications in the fields of electronics, material science, catalysis, and so on $[1,2]$. Therefore, a lot of experimental and theoretical studies have recently focused on the deposition of transition metal(s) onto graphene support and the interfaces between graphene and transition metals [1-5]. Moreover, graphene oxide was previously attracting a great attention mainly for the mass production of high-quality graphene through the reduction of graphene oxide [6]. However, many recent studies are focused on the inherent properties of graphene oxide because graphene oxide can modify the properties of graphene by controlling the functional groups related to oxygen and the defect site [6]. Chen et al. [7] and Wang et al. [8] have recently reported the synthesis of palladium nanoparticles on graphene oxide and shown clean and welldispersed Pd nanoparticles due to the strong anchoring of Pd onto a graphene oxide surface that prevents agglomeration of Pd clusters.

Despite the great recent interest in metal particles on graphene or graphene oxide substrates, fundamental studies of the physical and chemical properties of metal clusters on graphene or graphene oxide are still needed. Investigations on well-defined model systems can greatly aid the understanding of the properties of metal overlayers on graphene or graphene oxide support. Epitaxial and high-quality graphene has recently been grown on various substrate surfaces, such as metals and inorganic materials $[1,2,9]$ and, as a result, the systems of various metals on epitaxial graphene have been investigated. It has recently been shown that metal 
overlayers deposited onto metal-supported graphene layers can intercalate between the metal substrate and the graphene film at elevated temperatures $[10,11]$. Up to now, two distinct intercalation mechanisms of metals under the graphene layer have been proposed, based on the strength of interaction between metal and carbon [12]. While metals weakly interacting with carbon atoms in the graphene layer are shown to intercalate through extended defects (open edge and/or domain boundaries), metals strongly interacting with carbon atoms prefer to intercalate via an exchange mechanism [12]. The intercalation via exchange mechanism needs higher temperature than that through extended defects. Although graphene oxide has been known for a long time and several graphene oxide models have been proposed, its detailed structure and reaction between oxygen atoms and graphene are still not well-understood [13].

In this study, palladium was deposited onto oxygen-precovered graphene/Ru(0001) surfaces prepared by a hot filament method at room temperature. The thermal behavior and the properties of palladium clusters were then investigated with x-ray photoelectron spectroscopy (XPS) and infrared reflection absorption spectroscopy (IRAS) using adsorbed CO (pressure of $\mathrm{CO}=1.0 \times 10^{-6}$ Torr) as a probe molecule. Under low temperature annealing in vacuum, palladium clusters on oxygen-precovered graphene mainly form large planar domains and some of the palladium are intercalated between the graphene layer and $\mathrm{Ru}$ substrate. However, with further annealing to above the desorption temperature of oxygen, phenomena similar to that of Pd supported on pristine graphene layer are observed. Annealing at high temperature, the intercalation of all palladium between the graphene layer and $\mathrm{Ru}$ substrate was observed, and then Pd desorbed from the substrate at temperatures above $1100 \mathrm{~K}$. Even though the annealing induces the intercalation of palladium between graphene and ruthenium substrate and desorption 
of palladium, the topmost graphene layer remained intact similar to the system of Pd on pristine graphene.

\section{Experimental}

The detailed experimental setup and the data acquisition procedures have been discussed elsewhere [11, 14-16]. All the experiments were performed in an ultrahigh vacuum (UHV) surface analysis chamber equipped with x-ray photoelectron spectroscopy, low-energy electron diffraction (LEED), quadrupole mass spectrometry (QMS), and connected to an elevatedpressure cell with $\mathrm{KBr}$ windows for infrared reflection absorption spectroscopy measurements. The base pressure in both chambers was $\sim 1 \times 10^{-10}$ Torr. The $\mathrm{Ru}(0001)$ single crystal (Princeton Scientific Corp., diameter $=10 \mathrm{~mm}$ and thickness $=1 \mathrm{~mm}$ ) was spot-welded onto a U-shaped Ta wire (0.030 in. diameter) and a C-type thermocouple was spot-welded to the backside of the single crystal to measure the sample temperature. The Ru(0001) single crystal was cleaned by repeated cycles of Ar ion sputtering, oxidation at $1000 \mathrm{~K}$ and annealing up to $1900 \mathrm{~K}$ in UHV by electron beam bombardment, and the cleanliness of the surface was verified with XPS. The high quality epitaxial graphene layer was obtained by pyrolysis of ethylene on the clean $\mathrm{Ru}(0001)$ surface. The Ru substrate was annealed at $1400 \mathrm{~K}$ for $300 \mathrm{sec}$ and then the sample was rapidly cooled down under ethylene atmosphere $\left(1 \times 10^{-6}\right.$ Torr $)$. The quality of graphene layer was monitored with LEED and it was also confirmed with IRAS and temperature programmed desorption (TPD) with the adsorption of CO. Palladium was deposited at room temperature onto the graphene layer supported on $\mathrm{Ru}(0001)$ using a resistively heated palladium wire (Alfa Aesar; diameter $=0.25 \mathrm{~mm} ; 99.99 \%)$ and the palladium coverage was calibrated with respect to clean $\mathrm{Ru}$ by the break point of XPS peak ratio $(\mathrm{Pd} / \mathrm{Ru})$ [17]. Atomic oxygen was deposited to the 
clean graphene surface with the hot-filament method in oxygen atmosphere (the pressure of oxygen $=5 \times 10^{-6}$ Torr). The coverage of oxygen was estimated by the integration of the $\mathrm{O} 1 \mathrm{~s}$ XPS feature. XPS spectra were analyzed by XPSPeak 4.1 software. Infrared spectra were collected at $4 \mathrm{~cm}^{-1}$ resolution using a grazing angle of approximately $85^{\circ}$ to the surface normal. All the IR spectra collected were referenced to a background spectrum acquired from the sample prior to gas adsorption and taken under $\mathrm{CO}$ atmosphere $\left(1 \times 10^{-6}\right.$ Torr $)$ after saturation.

\section{Results and Discussion}

First of all, the quality of the prepared graphene layer was investigated by XPS and LEED in UHV as well as with IRAS of adsorbed CO. The infrared spectrum obtained from the graphene layer after $\mathrm{CO}$ exposure $\left(1 \times 10^{-6}\right.$ Torr of $\left.\mathrm{CO}\right)$ at room temperature showed no $\mathrm{CO}$ vibrational features [11]. Carbon monoxide is one of the best probe molecules to identify defect sites on metal surfaces. Due to the strong interaction of $\mathrm{CO}$ and $\mathrm{Ru}$, the vibrational features of $\mathrm{CO}$ should appear once the graphene layer is defective and $\mathrm{Ru}$ sites are exposed through the "holes" in the graphene. The frequency of CO feature in IRAS is $\sim 2055 \mathrm{~cm}^{-1}$ at saturation CO coverage on $\mathrm{Ru}(0001)$ as shown in the sample annealed at $1400 \mathrm{~K}$ in Figures 2 and 4. It indicates full coverage and continuous layer of carbon on the $\mathrm{Ru}$ substrate. In order to investigate the behavior of atomic oxygen on graphene/Ru(0001), XPS and IRAS were performed after deposition of atomic oxygen. Figure 1 (a) shows O 1s XP spectra of atomic oxygen on graphene/Ru(0001) as a function of atomic oxygen deposition time. Atomic oxygen was deposited onto graphene through a hot-filament method at a sample temperature of $\sim 300 \mathrm{~K}$. The broad peak of O 1s XPS feature was observed and the peak maximum centered at $\sim 530.7 \mathrm{eV}$ at low coverage of atomic oxygen. With further deposition of atomic oxygen the peak shifts to 
lower binding energy values and the feature becomes asymmetric. After 40 minutes of atomic oxygen deposition, the XPS feature shifts to $530.2 \mathrm{eV}$. A control experiment with corresponding amount of molecular oxygen at room temperature was performed in order to confirm the occurrence of molecular oxygen adsorption and/or reaction. No oxygen feature in XPS was observed on the perfect graphene layer after exposure to molecular oxygen. Our previous results [11] and data from other references $[18,19]$ substantiated that the graphene layers supported on metals or inorganic substrates show no adsorption of gas molecules such as $\mathrm{CO}$ at room temperature when the graphene layer fully covers the support. It indicates that the graphene layer is inert and stable and acts as a protective layer for the support. In addition, recent studies [20-24] reported that oxygen adsorption or intercalation at the graphene/metal interface happens at elevated temperature in molecular oxygen atmosphere. Specifically, Liao et al. [21] and Starodub et al. [22] observed oxygen adsorption at the graphene/metal interface in the range of oxygen pressure of $10^{-6}$ Torr and above $300{ }^{\circ} \mathrm{C}$. Recently, Dong et al. [20] observed oxygen intercalation at graphene $/ \mathrm{Ru}(0001)$ interface at and above $150{ }^{\circ} \mathrm{C}$ at an oxygen pressure of $\sim 0.5$ Torr and the XPS binding energy of intercalated oxygen was $529.9 \mathrm{eV}$ which is in good agreement with our observation $(530.2 \mathrm{eV})$. Vinogradoc et al. [25] reported that the binding energy of $\mathrm{O}$ in epoxy group formed on highly ordered pyrolytic graphite (HOPG), graphene/Ir(111), and $\mathrm{Pt}(111)$ is $531.1 \mathrm{eV}$ after deposition of atomic oxygen. Moreover, they observed that some of the atomic oxygen deposited onto supported graphene are intercalated between graphene and metal substrate and the binding energy of intercalated oxygen is lower than that of epoxy group [25]. From our results and from previous publications [20, 25], it is unambiguous that the broad O 1s XPS feature at low coverage of atomic oxygen is the combination of oxygen atoms on/in graphene layer and oxygen intercalated between graphene 
and $\mathrm{Ru}(0001)$ substrate. As the population of oxygen atoms increases, the intercalated oxygen feature is more intense. Figure 1 (b) shows IRAS spectra taken at room temperature as a function of annealing temperature. The background spectrum was taken at $300 \mathrm{~K}$ after deposition of atomic oxygen. It means that the background spectrum already contains information about oxygen and graphene, and, therefore, the variation of negative features as a function of annealing temperature represents the change from as-deposited atomic oxygen on graphene/Ru(0001). Up to the annealing temperature of $700-800 \mathrm{~K}$, the two features at 1063 and $997 \mathrm{~cm}^{-1}$ gradually decrease and then they are saturated at higher temperature annealing. From previous reports on graphene oxide [26-28], these two features at 1063 and $997 \mathrm{~cm}^{-1}$ are assigned to $\mathrm{C}-\mathrm{O}$ stretching and epoxy group vibrations, respectively. In summary, atomic oxygen deposition on $\mathrm{GR} / \mathrm{Ru}(0001)$ at $300 \mathrm{~K}$ resulted in both the intercalation of oxygen between the graphene film and the $\mathrm{Ru}(0001)$ substrate and the formation of functional groups on the graphene layers (primarily in the form of epoxides).

Figure 2 shows normalized XPS intensities of $\mathrm{Pd}, \mathrm{Ru}$, and $\mathrm{Pd} / \mathrm{Ru}$ collected during stepwise annealing of 0.25 monolayer equivalent (MLE) $\mathrm{Pd} /$ graphene/Ru(0001) (panel (a)) and 0.25 MLE Pd/O-graphene/Ru(0001) (panel (b)). After the desired amount of Pd was deposited onto the graphene (GR) or oxygen-precovered graphene (O-GR) layer at room temperature, the sample was annealed step-wise and changes in the two different systems were monitored by XPS and IRAS of adsorbed CO. The samples were kept at each annealing temperature for 5 minutes, and then cooled down to $\sim 300 \mathrm{~K}$. Figures 2 shows the series of infrared spectra collected during CO exposure $\left(1.0 \times 10^{-6}\right.$ Torr of CO) of the 0.25 MLE Pd on graphene layer (panel (c)) and on oxygen-precovered graphene (panel (d)) as a function of annealing temperature, respectively. The two series of IR spectra collected after annealing up to $1300 \mathrm{~K}$ show no evidence of CO 
adsorption on either system (pristine and oxygen-precovered graphene layers) and it indicates that the graphene layers did not experience any damage and remained intact up to that temperature. As the XPS results in Figure 2 (a) reveal, in the temperature range of $300-900 \mathrm{~K}$, the XPS intensity of Pd on the graphene layer gradually decreases with increasing annealing temperature. As we have previously discussed it in detail [11], this phenomenon can be explained by the agglomeration of Pd clusters deposited onto the graphene layer. As the sample temperature was increased, the mobility of Pd was sufficiently high due to the weak interaction between palladium and graphene to form large clusters. In the 300-900 $\mathrm{K}$ temperature range, as shown in Figure 2 (c), the IRAS of adsorbed CO shows gradual decrease of the CO intensity, which is a strong evidence for the agglomeration of Pd clusters. Above $900 \mathrm{~K}$ annealing temperature, however, the XPS intensity of Pd abruptly increases and continues to increase up to $1100 \mathrm{~K}$ and, concomitantly, that of Ru gradually decreases. The IRAS spectrum of adsorbed CO shows a significant reduction in intensity after annealing at $1000 \mathrm{~K}$ and the $\mathrm{CO}$ vibrational feature completely disappears at $1100 \mathrm{~K}$. Even though the $\mathrm{CO}$ feature is completely disappeared in the IRAS, the XPS intensity of Pd restores almost to the same value as its original intensity was, as shown in Figure 2 (a). These observations provide direct evidence that Pd clusters deposited onto the graphene layer intercalate between the graphene layer and the Ru substrate without any damage of the graphene layer at high annealing temperatures $(\sim 1000 \mathrm{~K})$. The gradual decrease in the intensity of Ru XPS signal demonstrates that spreading of the intercalated palladium layer occurred on the Ru substrate under the graphene layer. Further annealing above $1100 \mathrm{~K}$ results in the reduction of Pd and the increase in Ru XPS intensities due to the onset of Pd desorption at this temperature $[29,30]$. Therefore, the increase in the intensity of Ru XPS 
signal above $1100 \mathrm{~K}$ is attributed to the desorption of palladium, and, ultimately, the dissolution of the GR layer in the Ru substrate above $1300 \mathrm{~K}$.

The behaviour of the Pd overlayer ( 0.25 MLE) on the oxygen-precovered graphene layer is quite different from that of Pd on the pristine graphene layer. The XPS intensity of Pd and the $\mathrm{Pd}$ to $\mathrm{Ru}$ intensity ratio are both maintained at the constant values up to $1000 \mathrm{~K}$, whereas the XPS intensity of Ru gradually increases up to $800 \mathrm{~K}$ and then decreases until $1200 \mathrm{~K}$, as shown in Figure 2 (b). The slight increase of Ru XPS signal intensity up to $800 \mathrm{~K}$ originates from the oxygen desorption from the graphene layer and the intercalation of Pd between the graphene and the Ru substrate. On the other hand, the XPS intensity of Pd fluctuates with annealing at low temperature (up to $500 \mathrm{~K}$ ) and then maintains at a constant value. This phenomenon may be related to the initial intercalation of Pd between graphene and Ru substrate. The IRAS spectra in this temperature range unambiguously show the evidence of intercalation. The IR spectrum of adsorbed $\mathrm{CO}$ on the as-deposited Pd at $300 \mathrm{~K}$ shows two distinct features at 2090 and $1945 \mathrm{~cm}^{-1}$ corresponding to CO adsorption on large planar Pd domains. As previously mentioned, the atomic oxygen deposited onto pristine graphene forms two types of oxygen; one is on or in graphene (e.g., epoxy groups) and the other is intercalated. The oxygen on or in the graphene layer plays the role of anchoring site for Pd and palladium forms large planar domains on graphene. As a result, the IR spectrum recorded just after Pd deposition resembles that obtained after $\mathrm{CO}$ adsorption on $\mathrm{Pd}(111)$. This IR spectrum is consistent with that reported by Freund and co-workers [31] for the SFG signal of CO (pressure $=10^{-6} \mathrm{mbar}$ ) on $\operatorname{Pd}(111)$ at $250-$ $300 \mathrm{~K}$ and by Goodman and co-workers [32]. The latter group observed that the coverage of CO on $\mathrm{Pd}(111)$ at 190 and $350 \mathrm{~K}$ are 0.63 and $0.50 \mathrm{ML}$ and CO preferentially occupied bridge-bound sites at the coverage of CO higher than 0.5 ML. However, the possibility of the formation of 
defect-rich, planar Pd domains and/or large Pd domains consisting of small clusters cannot be ruled out completely, as a broad IR band is observed at $2000-1900 \mathrm{~cm}^{-1}$. Even though the IR band observed at $\sim 1980 \mathrm{~cm}^{-1}$ is one of the evidence of a defect-rich surface and/or small metal cluster [31,33], the peak intensity is much lower in comparison with CO/0.25 MLE Pd/GR at $300 \mathrm{~K}$. It indicates that the deposited Pd on oxidized graphene generally forms smooth planar domains with some defects and the populations of defects, steps and/or particle edges are much lower in the Pd/GRO systems than in the Pd/GR systems. However, after annealing at $400 \mathrm{~K}$, the intensity of this CO vibrational feature is significantly reduced, as shown in Figure 2 (d), and the XPS intensity of Pd is concomitantly reduced. Palladium that initially formed large planar domains intercalate between the graphene layer and the $\mathrm{Ru}$ substrate even at this low sample temperature. Surface oxygen species formed during atomic oxygen deposition strongly interact with the as-deposited Pd cluster. With further annealing to a higher temperature, the intercalated palladium spreads between the graphene and Ru before it desorbs above $1100 \mathrm{~K}$. As a result, IRAS spectra for the sample annealed above $500 \mathrm{~K}$ do not show any $\mathrm{CO}$ vibrational feature (all the Pd were intercalated). This observation indicates that there is no Pd on the graphene layer and the graphene layer does not have any defect sites at all that might have formed during the intercalation or subsequent annealing. With the annealing at very high temperature (above 1300 $\mathrm{K})$, a CO vibrational feature at $2055 \mathrm{~cm}^{-1}$ appears with high intensity as shown in Figure 2 (d) because the annealing at $1400 \mathrm{~K}$ causes the dissolution of graphene into $\mathrm{Ru}[11]$, just as we have seen it for the $\mathrm{Pd} / \mathrm{GR} / \mathrm{Ru}(0001)$ system above.

The thermal behavior of Pd clusters on pristine and oxygen-precovered graphene were further investigated at higher Pd coverages. Figure 3 (a) - (d) show the normalized XPS intensities of $\mathrm{Pd}$ and $\mathrm{Ru}$ as well as the $\mathrm{Pd} / \mathrm{Ru}$ intensity ratio for two different coverages of $\mathrm{Pd}(1$ 
and 2 MLE) on graphene (panel (a) and (b)), and on oxygen-precovered graphene (panel (c) and (d)), as a function of annealing temperature. Despite the different Pd coverages, the variation of XPS intensities of Pd shows a similar trend; for Pd on graphene, it gradually decreases with increasing annealing temperature in the temperature range of $300-900 \mathrm{~K}$ and for Pd on oxygenprecovered graphene, it slightly increases and then remains nearly constant. Eventually, in both cases, annealing at high temperatures (at and above $1100 \mathrm{~K}$ ) results in the desorption of palladium as evidenced by a steep decrease in the XPS intensity of Pd.

Figures 4 (a) - (d) show the corresponding series of IRAS spectra of adsorbed CO on Pd/GR/Ru(0001) (panels (a) and (b)) and on Pd/O-GR/Ru(0001) (panels (c) and (d)) systems with different coverages of palladium ( 1 and 2 MLE) under CO atmosphere $\left(1.0 \times 10^{-6}\right.$ Torr $)$. All the spectra were obtained at a sample temperature of $300 \mathrm{~K}$. For the systems of Pd supported on pristine graphene layer similar IRAS results as those of $0.25 \mathrm{MLE}$ of $\mathrm{Pd} / \mathrm{GR} / \mathrm{Ru}(0001)$ are seen. At annealing temperatures of $\sim 1000 \mathrm{~K}, \mathrm{CO}$ vibrational features are still visible, but their intensities decrease with increasing annealing temperature. For these systems, CO vibrational features at and below $800 \mathrm{~K}$ were not changed except their intensities. It indicates that the properties of Pd clusters are almost the same until palladium completely intercalates between graphene and $\mathrm{Ru}$ support. The intensity of the vibrational feature of adsorbed $\mathrm{CO}$ decreases dramatically after annealing the sample to $1000 \mathrm{~K}$, and it completely disappears between 1100 and $1300 \mathrm{~K}$, even under $\mathrm{CO}$ atmosphere. After annealing at $1400 \mathrm{~K}$, a new, high intensity feature appears at $2055 \mathrm{~cm}^{-1}$, which can be assigned to $\mathrm{CO}$ on $\mathrm{Ru}(0001)$, due to the dissolution of carbon into $\mathrm{Ru}[11]$.

For the systems in which Pd is supported on oxygen-precovered graphene, the IRAS spectra of adsorbed $\mathrm{CO}$ at higher coverages of $\mathrm{Pd}$ are somewhat different from that of $0.25 \mathrm{MLE}$ 
$\mathrm{Pd} / \mathrm{GR} / \mathrm{Ru}(0001)$ system, as shown in Figures 4 (c) for 1 MLE Pd and (d) for 2 MLE of Pd. After the deposition of $\mathrm{Pd}$ at room temperature on $\mathrm{O}-\mathrm{GR} / \mathrm{Ru}(0001)$, IRAS shows a pattern similar to that of adsorbed $\mathrm{CO}$ on Pd supported on pristine graphene and the only difference between the two systems is that the intensity is greatly reduced in the system in which Pd is deposited onto an oxygen-precovered graphene surface. At low Pd coverage (e.g. 0.25 MLE Pd) on the oxygen-precovered graphene, the amount of oxygen on the surface is sufficient to enable all the Pd to form 2D (planar) rafts. Surface oxygen present on the system primarily in the form of epoxides plays the role of anchoring sites for Pd, therefore, guiding the incoming palladium atoms to form 2D planar domains, instead of three-dimensional clusters. However, as the coverage of palladium increases, the amount of oxygen on the graphene surface becomes limited, i.e., the number of incoming Pd atoms exceeds that of surface oxygen species. This will ultimately results in the formation of a Pd overlayer in which the metal is present in two distinct forms: some of the palladium is anchored to oxygen atoms, while the excess palladium forms three-dimensional clusters, similarly to those we observed for Pd deposition onto a pristine graphene layer. Therefore, the IRAS patterns of adsorbed $\mathrm{CO}$ for higher coverages of Pd are very similar to those observed for Pd on pristine graphene, although the integrated intensities are greatly reduced. Significant changes in the IR spectra of adsorbed CO are observed for the $\mathrm{Pd} / \mathrm{O}-\mathrm{GR} / \mathrm{Ru}(0001)$ systems with high Pd coverage ( $\geq 1 \mathrm{MLE}$ ) in the $300-600 \mathrm{~K}$ temperature range. In this temperature range, the intensities of the IR features of Pd cluster-adsorbed $\mathrm{CO}$ are reduced, and new bands appear at 2080 and $1940 \mathrm{~cm}^{-1}$, similar to IR features of adsorbed CO on $\operatorname{Pd}(111)$. The possibility of the formation of PdO [34] cannot be ruled out completely, but no evidence from XPS measurements substantiates the formation of PdO (after $600 \mathrm{~K}$ annealing practically no intensity of the $\mathrm{O} 1 \mathrm{~s}$ XPs feature was observed). In addition, because the new 
IRAS features appearing during low temperature (up to $600 \mathrm{~K}$ ) annealing are stable up to1000 K that is higher than the decomposition temperature of $\mathrm{PdO}(720$ - $850 \mathrm{~K})$ [35]. The Pd overlayer structure formed in the $300-700 \mathrm{~K}$, however, seems to be different from that present after annealing at 800 and $1000 \mathrm{~K}$. The main difference in the samples in these two temperature regimes is the presence $(300-700 \mathrm{~K})$ and complete absence of oxygen $(800-1000 \mathrm{~K})$. The $\mathrm{Pd}$ clusters formed during deposition at $300 \mathrm{~K}$ form 2D rafts on the GR layer and this Pd overlayer is primarily responsible for the development of the IR feature of adsorbed CO at $\sim 1940 \mathrm{~cm}^{-1}$. Above $700 \mathrm{~K}$ annealing all the intercalated oxygen is removed, and the Pd overlayer on the graphene layer interacts strongly with the intercalated Pd layer uniformly spread over the $\mathrm{Ru}$ substrate. This Pd overlayer is responsible for the IR feature of adsorbed CO at $\sim 2075 \mathrm{~cm}^{-1}$. Interestingly, this Pd layer is more thermally stable than Pd clusters deposited onto a pristine graphene layer. This is manifested in the higher temperature needed for the intercalation of the 2D Pd layer between the graphene layer and Ru substrate in this latter case. Annealing the samples above $1100 \mathrm{~K}$ brings about the onset of the desorption of intercalated Pd, and above $1300 \mathrm{~K}$ the dissolution of graphene into the Ru substrate.

\section{Conclusions}

The thermal behavior of Pd on pristine graphene and atomic oxygen-exposed graphene on $\mathrm{Ru}(0001)$ support have been investigated in the temperature range of $300-1400 \mathrm{~K}$ by XPS and IRAS of adsorbed CO. IRAS spectra of the oxygen-exposed GR/Ru(0001) surface suggest that atomic oxygen exposure results in the formation of epoxy groups primarily. The oxygenprecovered graphene $/ \mathrm{Ru}(0001)$ surface was prepared by the hot filament method under oxygen atmosphere at $300 \mathrm{~K}$ of substrate temperature. Palladium clusters on pristine graphene 
agglomerated as the annealing temperature increased and intercalated between the graphene layer and the metal substrate starting above $900 \mathrm{~K}$. On the oxygen-precovered graphene, Pd at the low coverage of Pd (0.25 MLE) mainly formed large planar domains (spreading of Pd on the oxidized graphene layer) and intercalated between the graphene layer and the Ru substrate at lower temperature due to the interaction between $\mathrm{Pd}$ and intercalated oxygen (no adsorbed $\mathrm{CO}$ on Pd was observed above $400 \mathrm{~K}$ annealing). At higher temperatures, both systems experience the same phenomenon, i.e., the intercalation of all of palladium between the graphene layer and Ru substrate. The intercalated Pd layer desorbed from the substrate at temperatures $>1100 \mathrm{~K}$. The IR spectra of adsorbed CO at Pd coverages $\geq 1$ MLE showed identical features regardless whether the graphene layer was exposed to atomic oxygen or not. The much lower intensities of the IR features of adsorbed $\mathrm{CO}$ on the as-deposited $\mathrm{Pd}$ on the oxidized GR/Ru(0001) system, in comparison to that on the pristine graphene, indicated that the Pd particles were much smaller on the O-GR layer than on the pristine graphene. Annealing these samples from 300 to $700 \mathrm{~K}$ seems to result in significant changes in the structure of the Pd overlayer on the oxidized GR layer. Similarly to that we have seen for the $0.25 \mathrm{MLE} \mathrm{Pd} / \mathrm{O}-\mathrm{GR} /(\mathrm{Ru}(0001)$ system, some of the Pd (that formed a spread layer on the O-GR) intercalated between the GR and the Ru substrate, while the small Pd particles spread on the surface. The structure of the Pd overlayer after the $800 \mathrm{~K}$ annealing cycle seems to be very different from that observed at $300 \mathrm{~K}$. The Pd that was present in small clusters spread out on the graphene surface due to the interaction with the intercalated Pd layer through the graphene film. This interaction stabilized the Pd film and even after $1000 \mathrm{~K}$ annealing the metal film was stable. After even higher temperature annealing all the Pd intercalated, and then desorbed above $1100 \mathrm{~K}$. Interestingly, after the intercalation and desorption of $\mathrm{Pd}$, the graphene layer preserved its perfect structure (i.e., continuity) without any 
damage. Annealing at and above $1350 \mathrm{~K}$, the graphene layer is dissolved into Ru bulk and, as the result, bare $\mathrm{Ru}$ site is exposed.

\section{Acknowledgments}

We gratefully acknowledge the US Department of Energy (DOE), Office of Science, Office of Basic Energy Sciences, Chemical Sciences, Geosciences, and Biosciences Division for the support of this work. The research described in this article was performed at the Environmental Molecular Sciences Laboratory (EMSL), a national scientific user facility sponsored by the DOE Office of Biological and Environmental Research and located at Pacific Northwest National Laboratory (PNNL). PNNL is operated for the US DOE by Battelle Memorial Institute under contract number DE-AC05-76RL01830. CWY gratefully acknowledges the support of this work by the Sungshin Women's University Research Grant of 2015. 


\section{References}

[1] M. Batzill, The surface science of graphene: Metal interfaces, CVD synthesis, nanoribbons, chemical modifications, and defects, Surf. Sci. Rep., 67 (2012) 83-115.

[2] A. Dahal, M. Batzill, Graphene-nickel interfaces: a review, Nanoscale, 6 (2014) 2548-2562.

[3] K. Gotterbarm, C. Bronnbauer, U. Bauer, C. Papp, H.P. Steinruck, Graphene-Supported Pd Nanoclusters Probed by Carbon Monoxide Adsorption, J. Phys. Chem. C, 118 (2014) 25097-25103.

[4] K. Gotterbarm, C. Steiner, C. Bronnbauer, U. Bauer, H.P. Steinruck, S. Maier, C. Papp, GrapheneTemplated Growth of Pd Nanoclusters, J. Phys. Chem. C, 118 (2014) 15934-15939.

[5] Q. Liao, H.J. Zhang, K. Wu, H.Y. Li, S.N. Bao, P. He, INTERCALATION OF COBALT UNDERNEATH A MONOLAYER OF GRAPHENE ON Ru(0001), Surf. Rev. Lett., 19 (2012) 5.

[6] S.J. Baek, W.G. Hong, M. Park, T. Claeson, H.J. Kim, B.H. Kim, Y.W. Park, Electrical conduction of palladium-decorated multi-layered graphene oxide effected by hydrogen dissociation, Synth. Met., 199 (2015) 74-78.

[7] X. Chen, G. Wu, J. Chen, X. Chen, Z. Xie, X. Wang, Synthesis of "Clean" and Well-Dispersive Pd Nanoparticles with Excellent Electrocatalytic Property on Graphene Oxide, J. Am. Chem. Soc., 133 (2011) 3693-3695.

[8] Q. Wang, X. Cui, W. Guan, W. Zheng, J. Chen, X. Zheng, X. Zhang, C. Liu, T. Xue, H. Wang, Z. Jin, H. Teng, Synthesis of flower-shape palladium nanostructures on graphene oxide for electrocatalytic applications, Journal of Physics and Chemistry of Solids, 74 (2013) 1470-1474.

[9] Y. Cui, J.F. Gao, L. Jin, J.J. Zhao, D.L. Tan, Q. Fu, X.H. Bao, An Exchange Intercalation Mechanism for the Formation of a Two-Dimensional Si Structure Underneath Graphene, Nano Res., 5 (2012) 352-360. [10] G. Li, H. Zhou, L. Pan, Y. Zhang, L. Huang, W. Xu, S. Du, M. Ouyang, A.C. Ferrari, H.-J. Gao, Role of Cooperative Interactions in the Intercalation of Heteroatoms between Graphene and a Metal Substrate, J. Am. Chem. Soc., (2015).

[11] C.-W. Yi, J. Szanyi, Surf. Sci., 641 (2015) 154-158.

[12] L. Jin, Q. Fu, Y. Yang, X.H. Bao, A comparative study of intercalation mechanism at graphene/Ru(0001) interface, Surf. Sci., 617 (2013) 81-86.

[13] J.F. Dai, G.J. Wang, L. Ma, C.K. Wu, Study on the surface energies and dispersibility of graphene oxide and its derivatives, J. Mater. Sci., 50 (2015) 3895-3907.

[14] C.-W. Yi, J.H. Kwak, C.H.F. Peden, C. Wang, J. Szanyi, Understanding practical catalysts using a surface science approach: The importance of strong interaction between $\mathrm{BaO}$ and $\mathrm{Al} 2 \mathrm{O} 3$ in NOx storage materials, J. Phys. Chem. C, 111 (2007) 14942-14944.

[15] C.-W. Yi, J.H. Kwak, J. Szanyi, Interaction of NO2 with BaO: From cooperative adsorption to $\mathrm{Ba}(\mathrm{NO3})(2)$ formation, J. Phys. Chem. C, 111 (2007) 15299-15305.

[16] C.-W. Yi, J. Szanyi, D2O adsorption on an ultrathin alumina film on NiAl(110), J. Phys. Chem. C, 111 (2007) 17597-17602.

[17] C.W. Yi, K. Luo, T. Wei, D.W. Goodman, The composition and structure of Pd-Au surfaces, J. Phys. Chem. B, 109 (2005) 18535-18540.

[18] L. Jin, Q. Fu, A.Y. Dong, Y.X. Ning, Z.J. Wang, H. Bluhm, X.H. Bao, Surface Chemistry of CO on Ru(0001) under the Confinement of Graphene Cover, J. Phys. Chem. C, 118 (2014) 12391-12398. [19] M. Papagno, D. Pacile, D. Topwal, P. Moras, P.M. Sheverdyaeva, F.D. Natterer, A. Lehnert, S. Rusponi, Q. Dubout, F. Calleja, E. Frantzeskakis, S. Pons, J. Fujii, I. Vobornik, M. Grioni, C. Carbone, H. Brune, Two Distinct Phases of Bilayer Graphene Films on Ru(0001), ACS Nano, 6 (2012) 9299-9304. [20] A. Dong, Q. Fu, M. Wei, Y. Liu, Y. Ning, F. Yang, H. Bluhm, X. Bao, Facile oxygen intercalation between full layer graphene and Ru(0001) under ambient conditions, Surf. Sci., 634 (2015) 37-43. 
[21] Q. Liao, H.J. Zhang, K. Wu, H.Y. Li, S.N. Bao, P. He, Oxidation of graphene on Ru(0001) studied by scanning tunneling microscopy, Appl. Surf. Sci., 257 (2010) 82-86.

[22] E. Starodub, N.C. Bartelt, K.F. McCarty, Oxidation of Graphene on Metals, J. Phys. Chem. C, 114 (2010) 5134-5140.

[23] P. Sutter, J.T. Sadowski, E.A. Sutter, Chemistry under Cover: Tuning Metal-Graphene Interaction by Reactive Intercalation, J. Am. Chem. Soc., 132 (2010) 8175-8179.

[24] H. Zhang, Q. Fu, Y. Cui, D.L. Tan, X.H. Bao, Growth Mechanism of Graphene on Ru(0001) and O-2 Adsorption on the Graphene/Ru(0001) Surface, J. Phys. Chem. C, 113 (2009) 8296-8301.

[25] N.A. Vinogradov, K. Schulte, M.L. Ng, A. Mikkelsen, E. Lundgren, N. Mårtensson, A.B. Preobrajenski, Impact of Atomic Oxygen on the Structure of Graphene Formed on $\operatorname{Ir}(111)$ and Pt(111), The Journal of Physical Chemistry C, 115 (2011) 9568-9577.

[26] A.B. Bourlinos, D. Gournis, D. Petridis, T. Szabó, A. Szeri, I. Dékány, Graphite Oxide: Chemical Reduction to Graphite and Surface Modification with Primary Aliphatic Amines and Amino Acids, Langmuir, 19 (2003) 6050-6055.

[27] G. Goncalves, P.A.A.P. Marques, C.M. Granadeiro, H.I.S. Nogueira, M.K. Singh, J. Grácio, Surface Modification of Graphene Nanosheets with Gold Nanoparticles: The Role of Oxygen Moieties at Graphene Surface on Gold Nucleation and Growth, Chemistry of Materials, 21 (2009) 4796-4802. [28] N.I. Kovtyukhova, P.J. Ollivier, B.R. Martin, T.E. Mallouk, S.A. Chizhik, E.V. Buzaneva, A.D. Gorchinskiy, Layer-by-Layer Assembly of Ultrathin Composite Films from Micron-Sized Graphite Oxide Sheets and Polycations, Chemistry of Materials, 11 (1999) 771-778.

[29] D.E. Pierce, R.P. Burns, K.A. Gabriel, THERMAL-DESORPTION SPECTROSCOPY OF PALLADIUM AND COPPER ON SILICA, Thin Solid Films, 206 (1991) 340-344.

[30] J. Storm, R.M. Lambert, N. Memmel, J. Onsgaard, E. Taglauer, Catalysis with monometallic and bimetallic films: Trimerization of acetylene to benzene on $\mathrm{Pd} / \mathrm{Ru}(001)$ and $(\mathrm{Pd}+\mathrm{Au}) / \mathrm{Ru}(001)$, Surf. Sci., 436 (1999) 259-268.

[31] H. Unterhalt, G. Rupprechter, H.-J. Freund, Vibrational Sum Frequency Spectroscopy on Pd(111) and Supported Pd Nanoparticles: CO Adsorption from Ultrahigh Vacuum to Atmospheric Pressure ${ }^{\dagger}$, The Journal of Physical Chemistry B, 106 (2002) 356-367.

[32] J. Szanyi, W.K. Kuhn, D.W. Goodman, CO adsorption on $\mathrm{Pd}(111)$ and $\mathrm{Pd}(100)$ : Low and high pressure correlations, Journal of Vacuum Science \&amp; Technology A, 11 (1993) 1969-1974.

[33] G. Rupprechter, H. Unterhalt, M. Morkel, P. Galletto, L. Hu, H.-J. Freund, Sum frequency generation vibrational spectroscopy at solid-gas interfaces: $\mathrm{CO}$ adsorption on $\mathrm{Pd}$ model catalysts at ambient pressure, Surf. Sci., 502-503 (2002) 109-122.

[34] N.M. Martin, M. Van den Bossche, H. Grönbeck, C. Hakanoglu, F. Zhang, T. Li, J. Gustafson, J.F. Weaver, E. Lundgren, CO Adsorption on Clean and Oxidized Pd(111), The Journal of Physical Chemistry C, 118 (2014) 1118-1128.

[35] J.A. Hinojosa, J.F. Weaver, Surface structural evolution during the thermal decomposition of a PdO(101) thin film, Surf. Sci., 605 (2011) 1797-1806. 


\section{Figure Captions}

Figure 1. (a) O 1s XP spectra: atomic oxygen deposition on graphene/Ru(0001). (b) IR spectra of oxygen-precovered graphene/Ru(0001) as a function of annealing temperature. (The background spectrum was taken at $300 \mathrm{~K}$ after the deposition of atomic oxygen and the series of spectra were taken after cooling the sample down to room temperature.)

Figure 2. Summary of XPS measurements (a) 0.25 MLE of Pd on pristine graphene and (b) 0.25 MLE of Pd on oxygen-precovered graphene as a function of annealing temperature, and the corresponding series of IRAS spectra $((c)$ and $(d))$ under CO atmosphere $(\mathrm{P}(\mathrm{CO})=1 \times$ $10^{-6}$ Torr) taken at room temperature.

Figure 3. Summary of XPS spectroscopy of (a) 1.0 MLE of Pd and (b) 2.0 MLE of Pd on pristine graphene and (c) 1.0 MLE of Pd and (d) 2.0 MLE of Pd on oxygen-precovered graphene as a function of annealing temperature.

Figure 4. A series of IRAS of (a) 1.0 MLE of Pd and (b) 2.0 MLE of Pd on pristine graphene and (c) 1.0 MLE of Pd and (d) 2.0 MLE of Pd on oxygen-precovered graphene. The indicated temperature is the annealing temperature and IRAS were taken under CO atmosphere (pressure $=1 \times 10^{-6}$ Torr) at room temperature. 


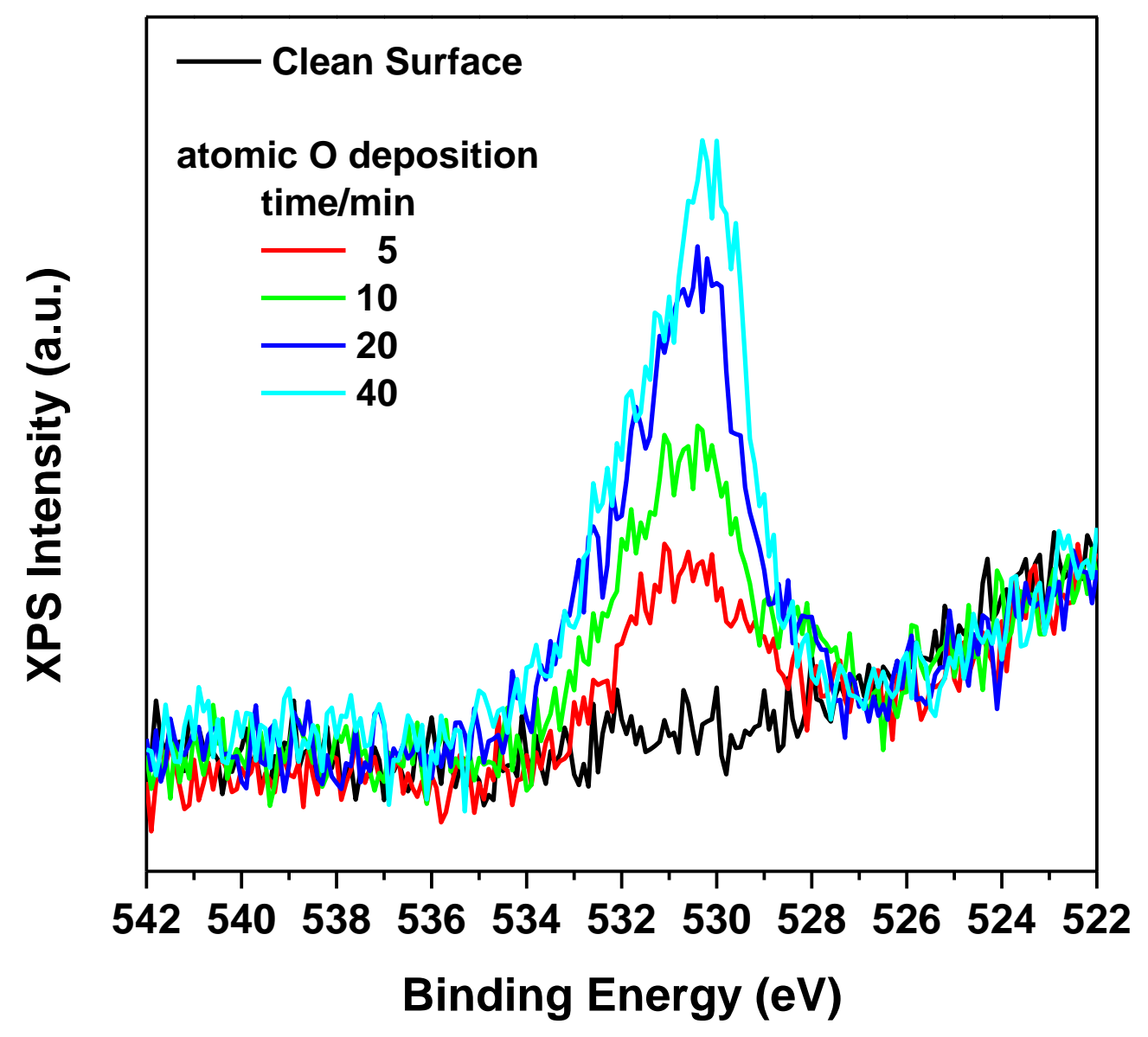

Figure 1 (a) Yi et al. 


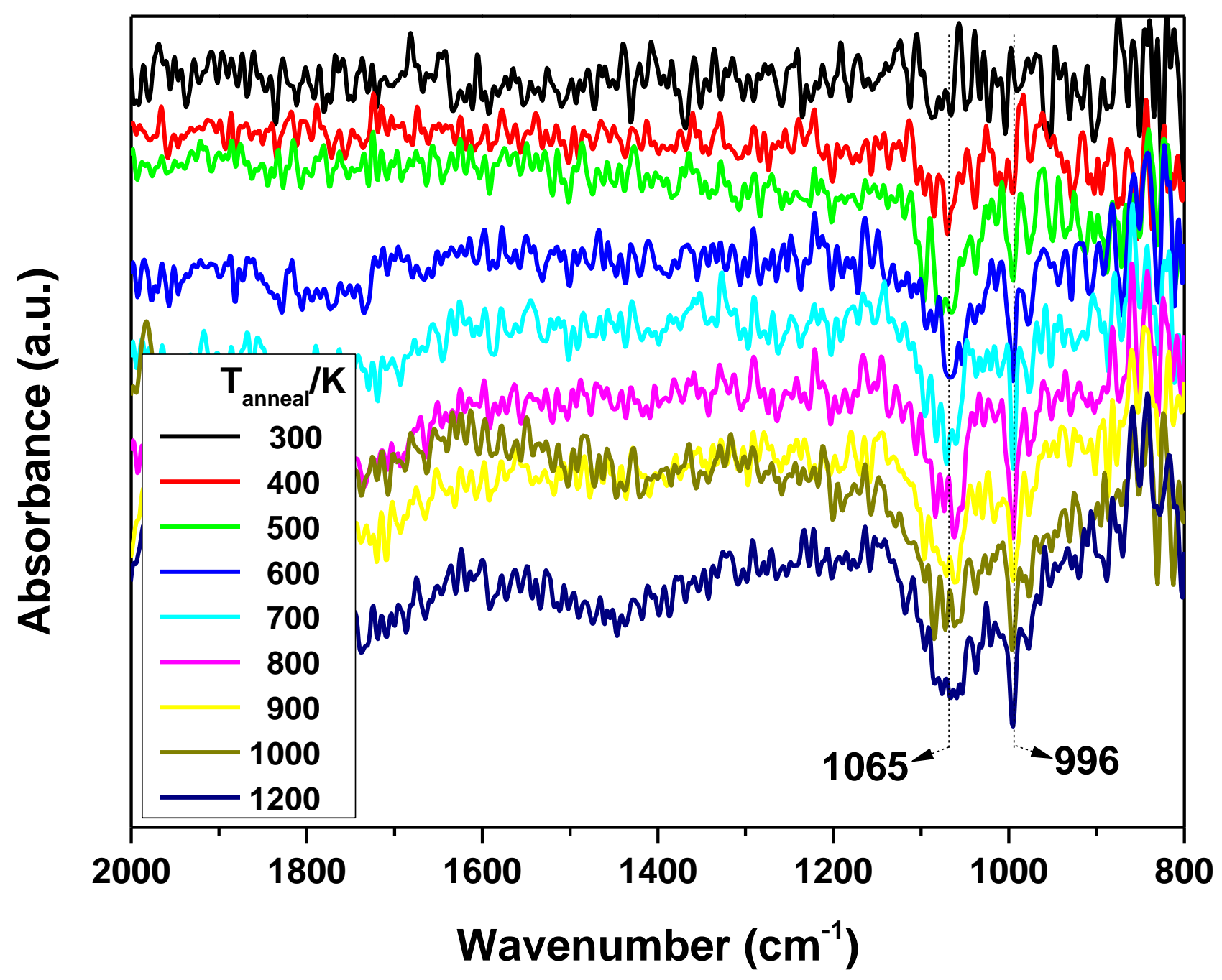

Figure 1 (b) Yi et al. 


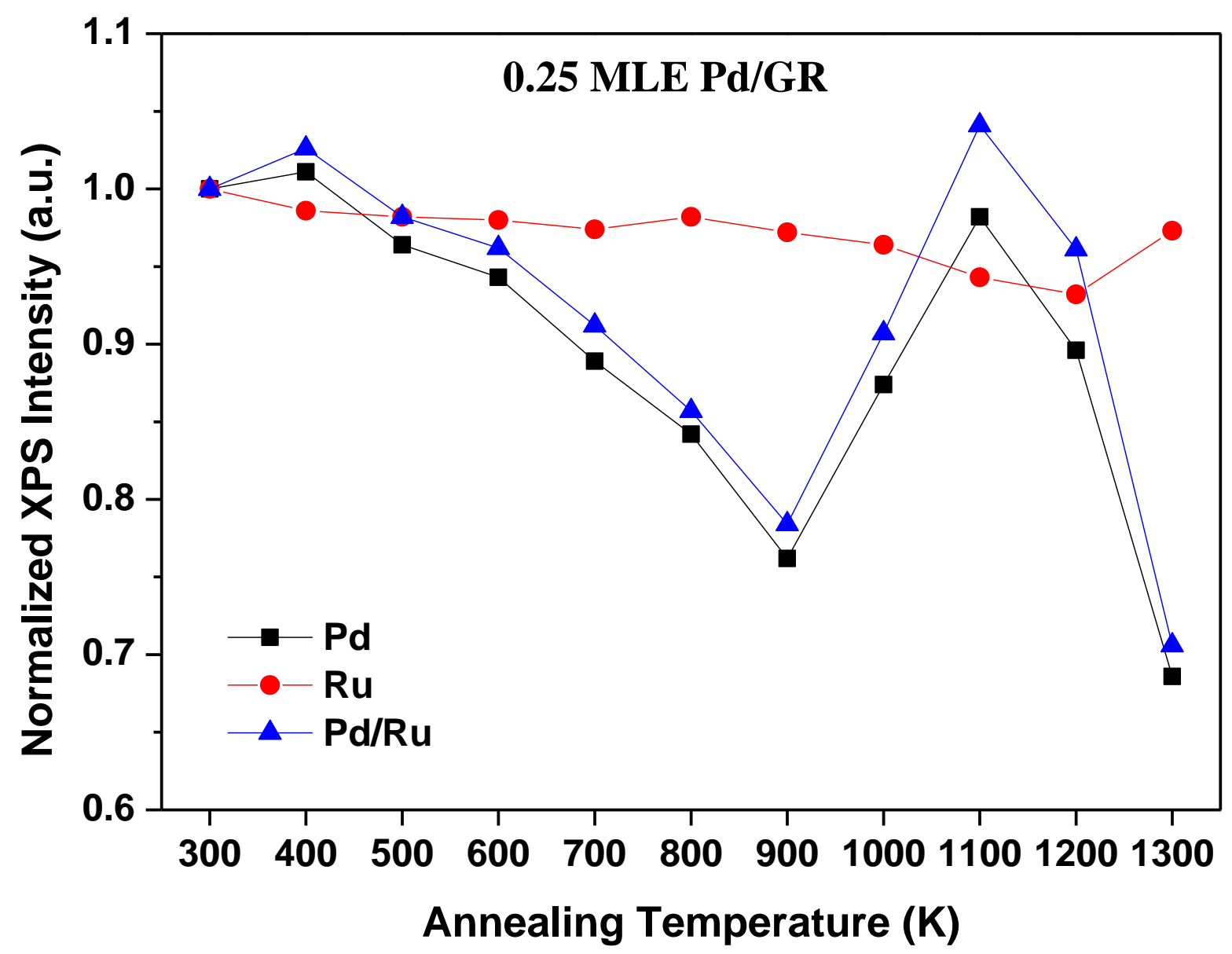

Figure 2 (a) Yi et al. 


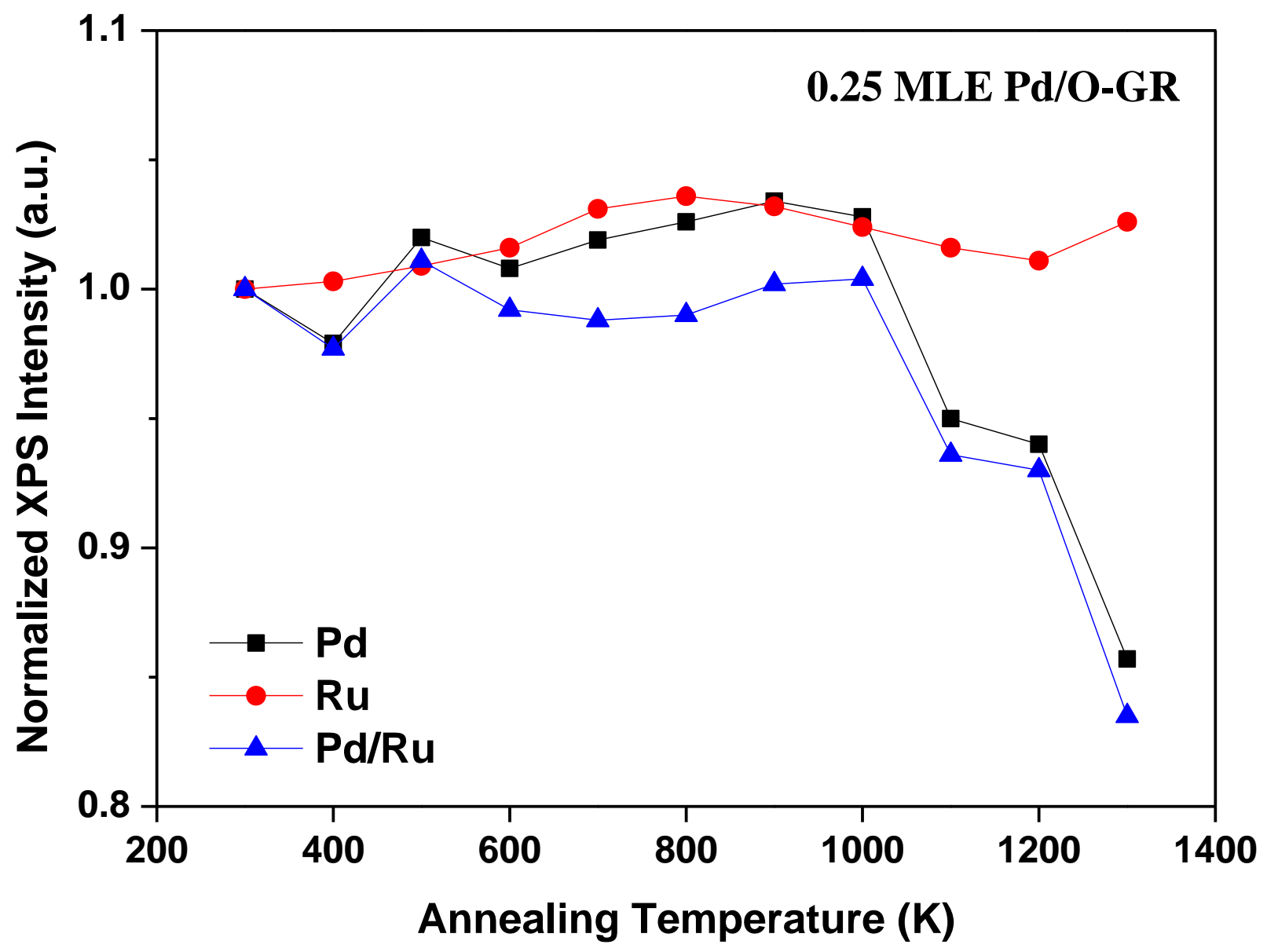

Figure 2 (b) Yi et al. 


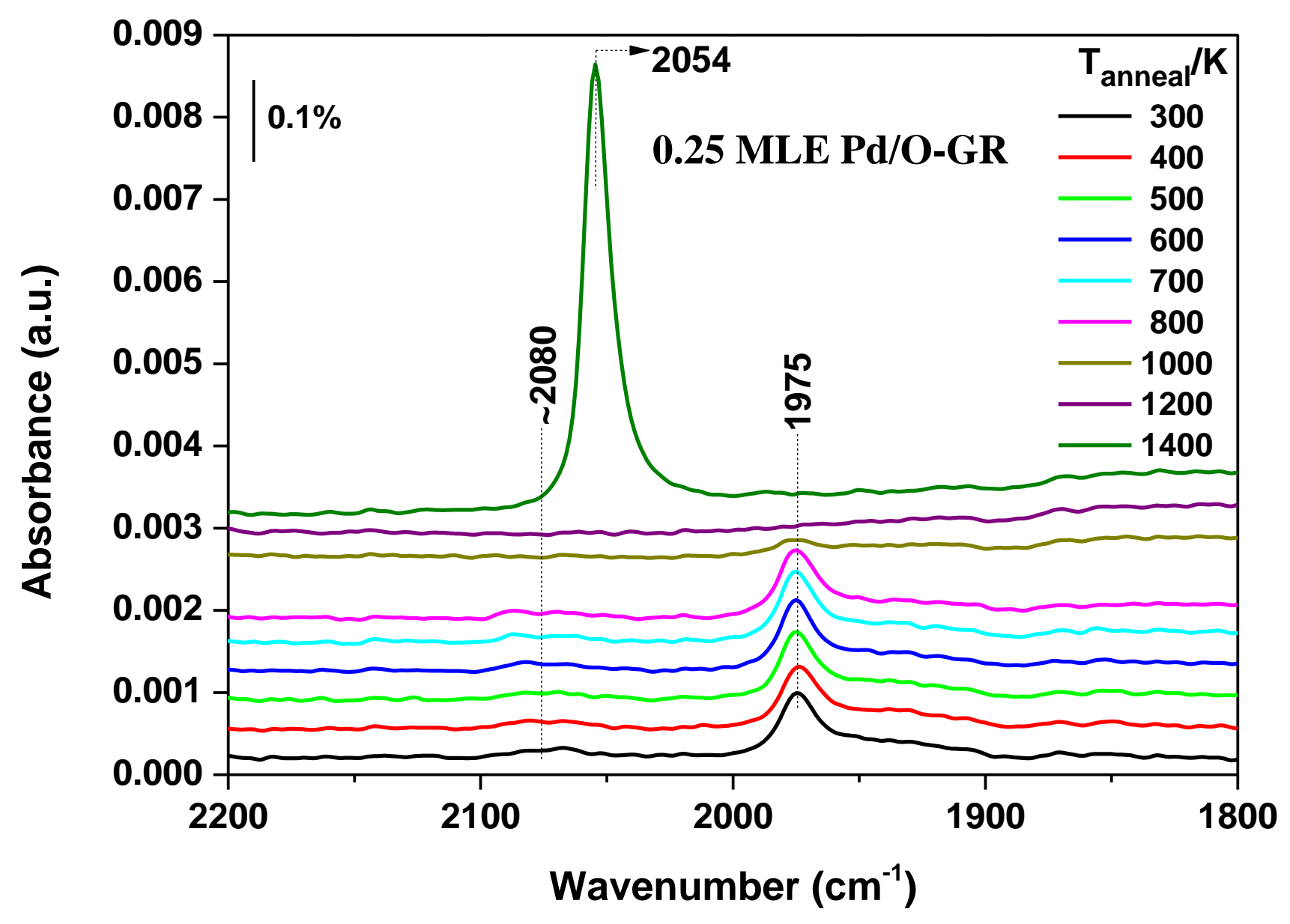

Figure 2 (c) Yi et al. 


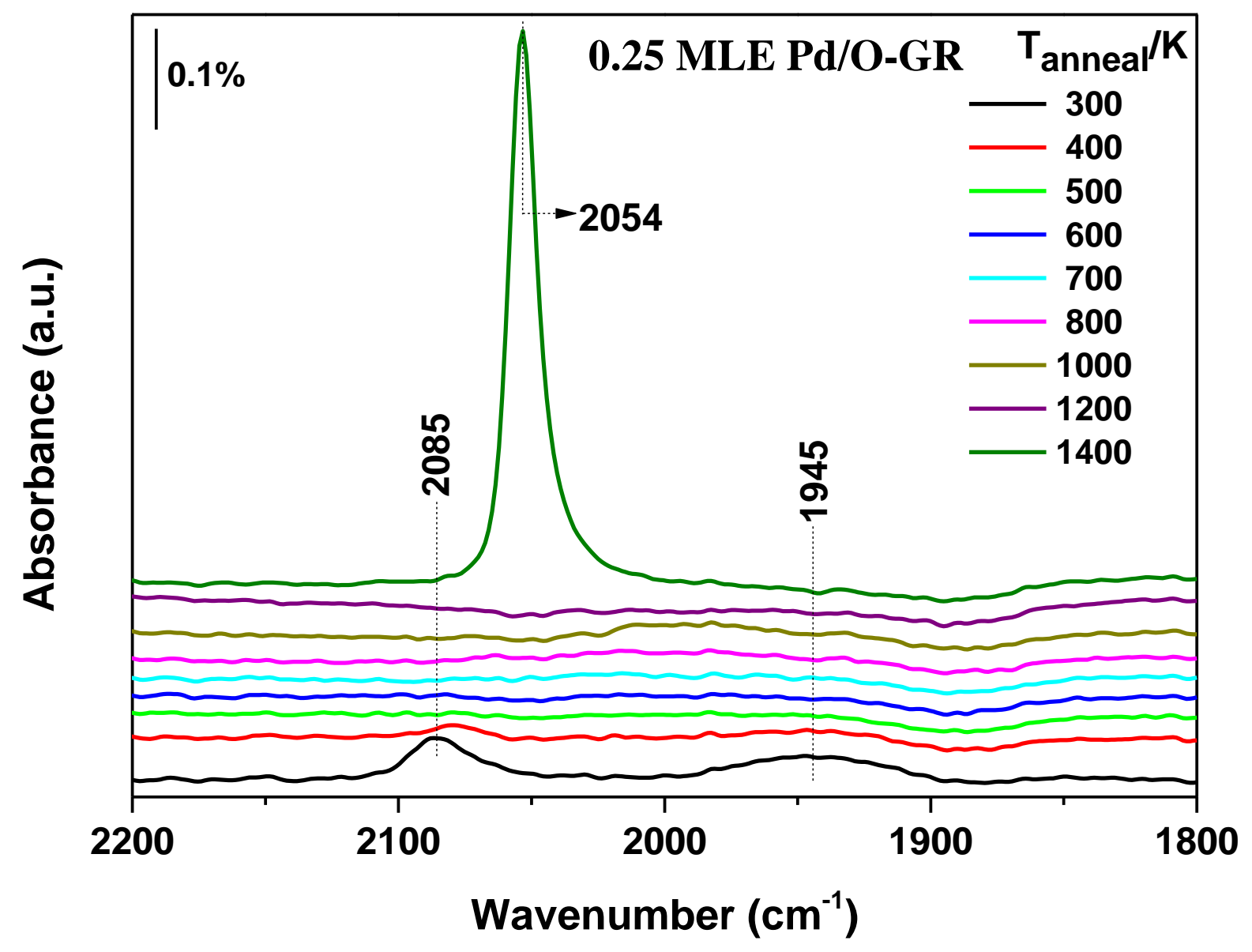

Figure 2 (d) Yi et al. 


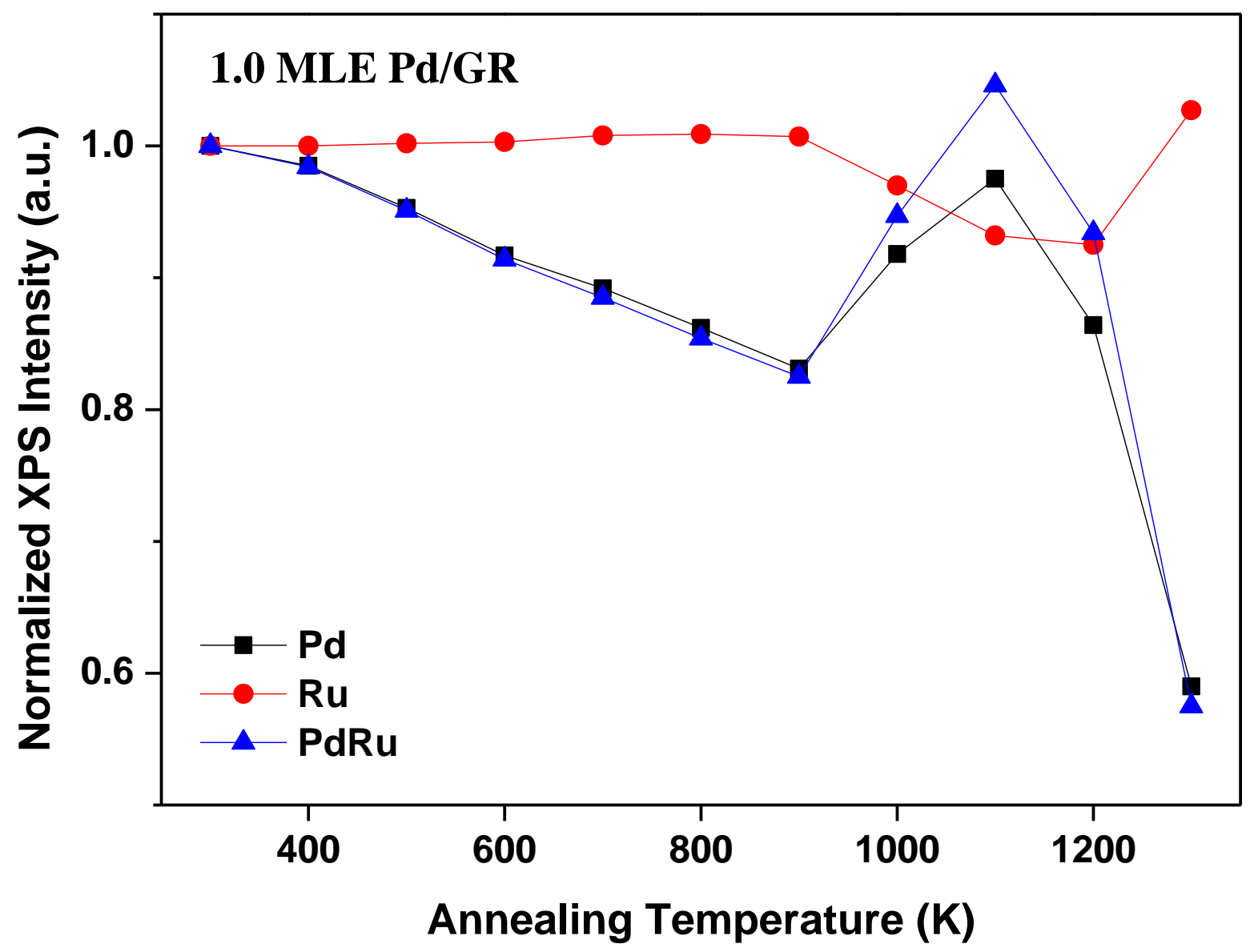

Figure 3 (a) Yi et.al 


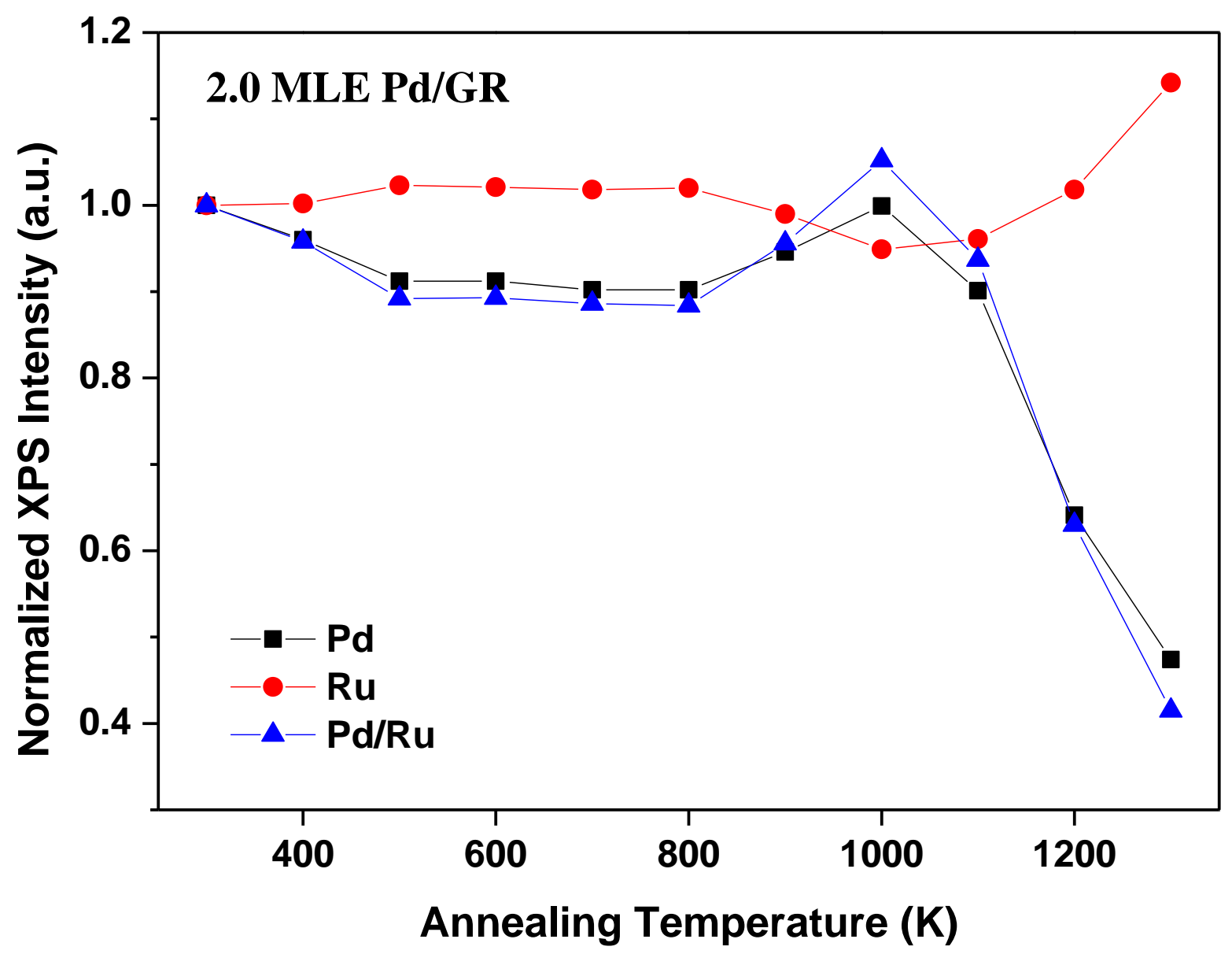

Figure 3 (b) Yi et.al 


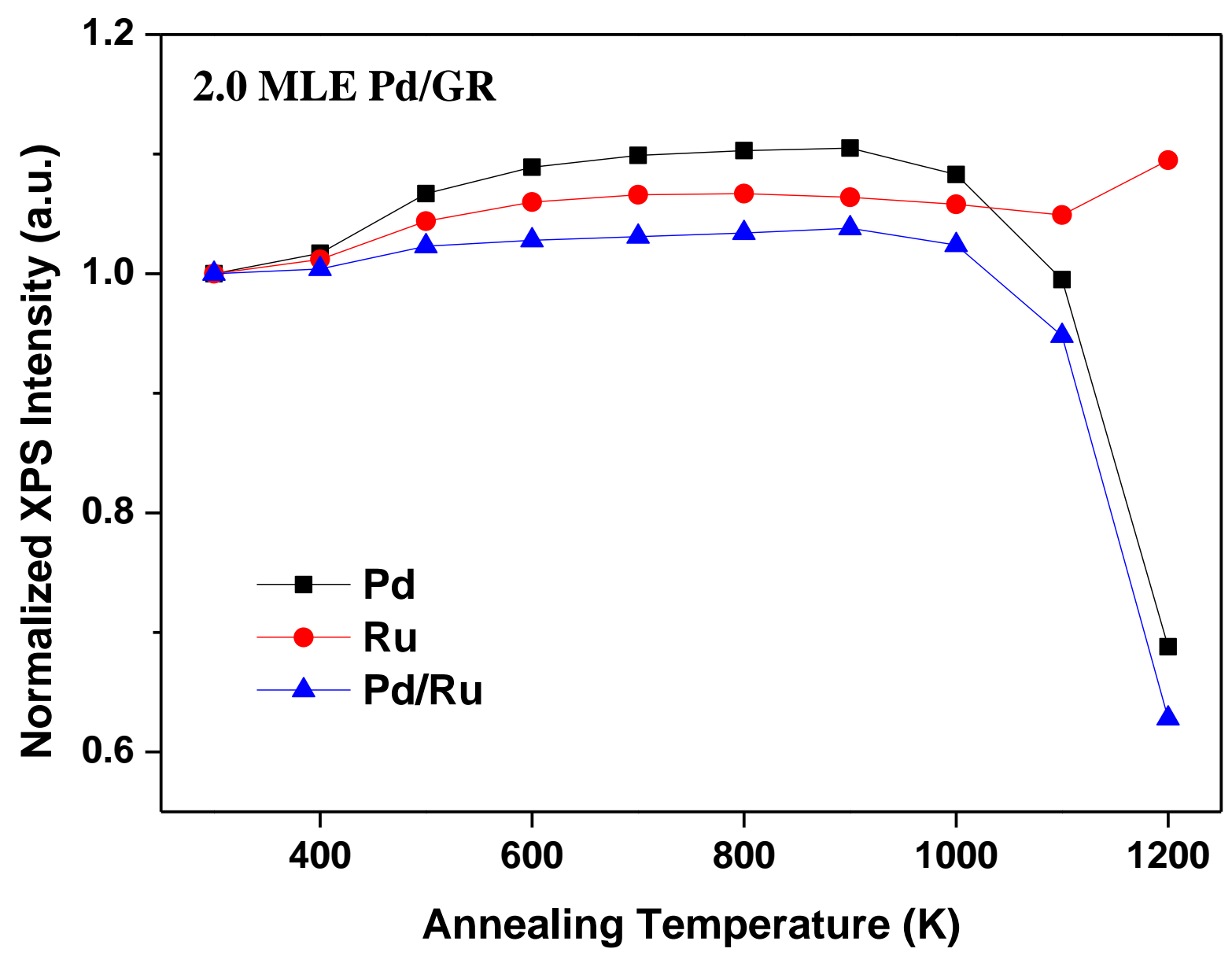

Figure 3 (c) Yi et al. 


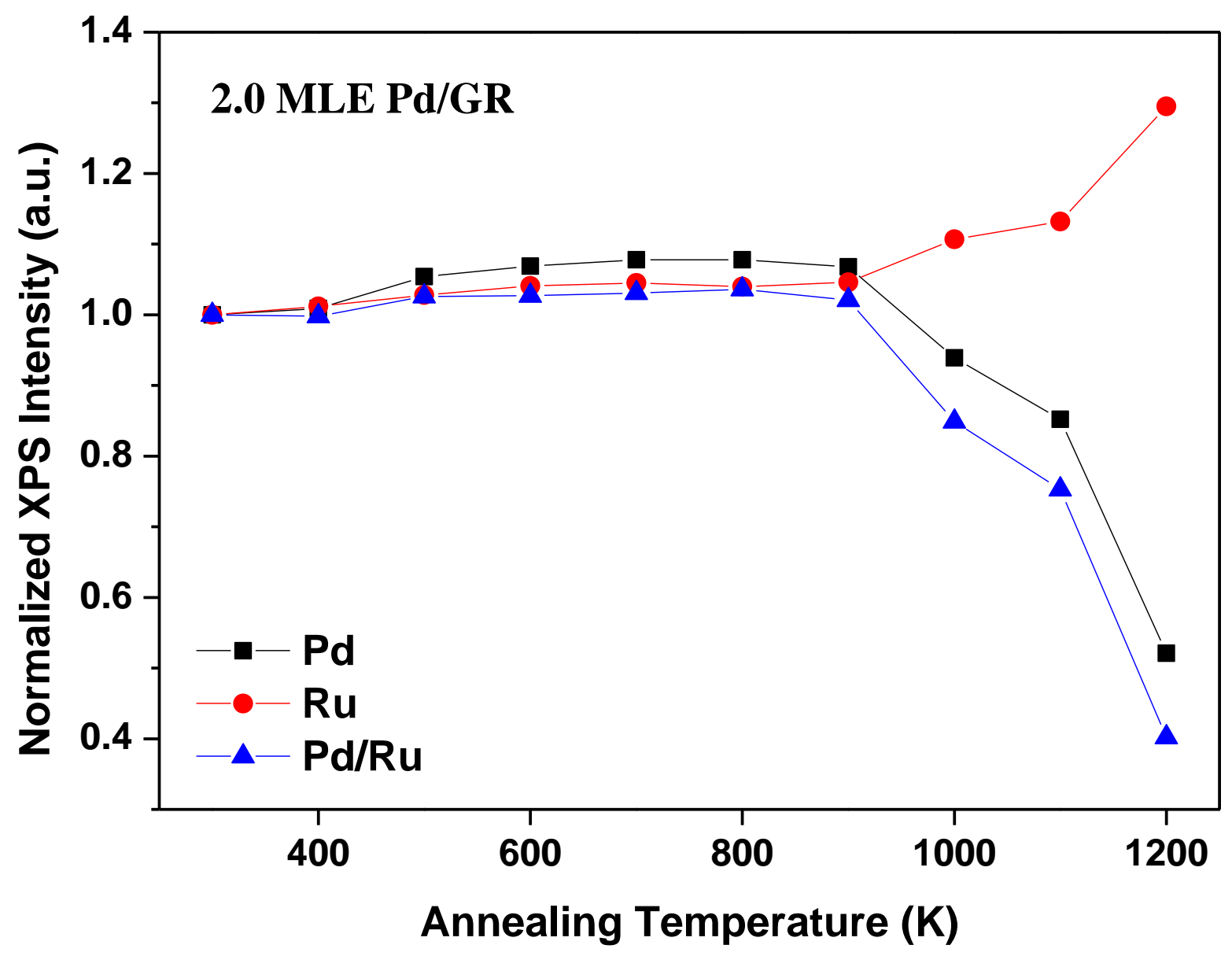

Figure 3 (d) Yi et al. 


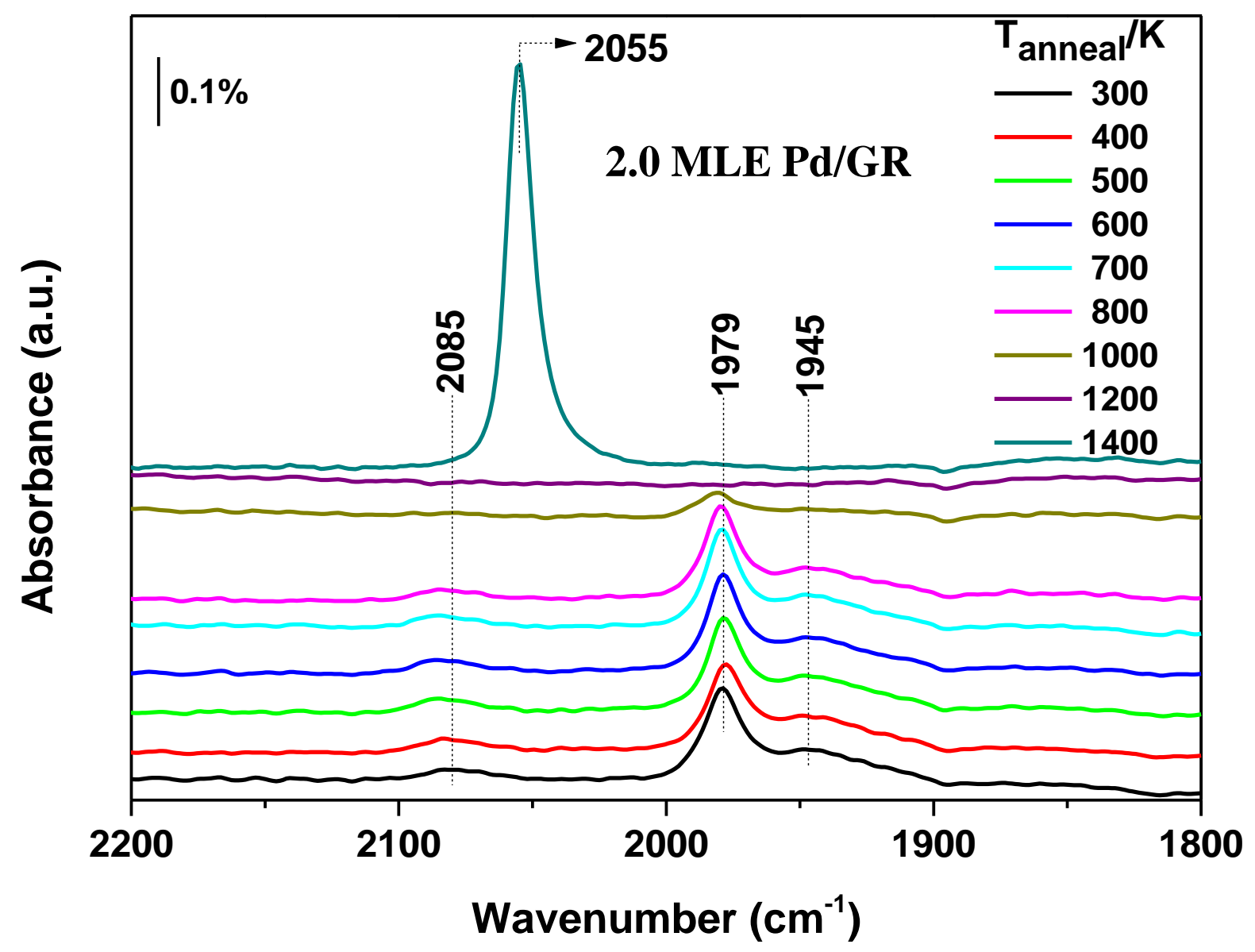

Figure 4 (a) Yi et.al 


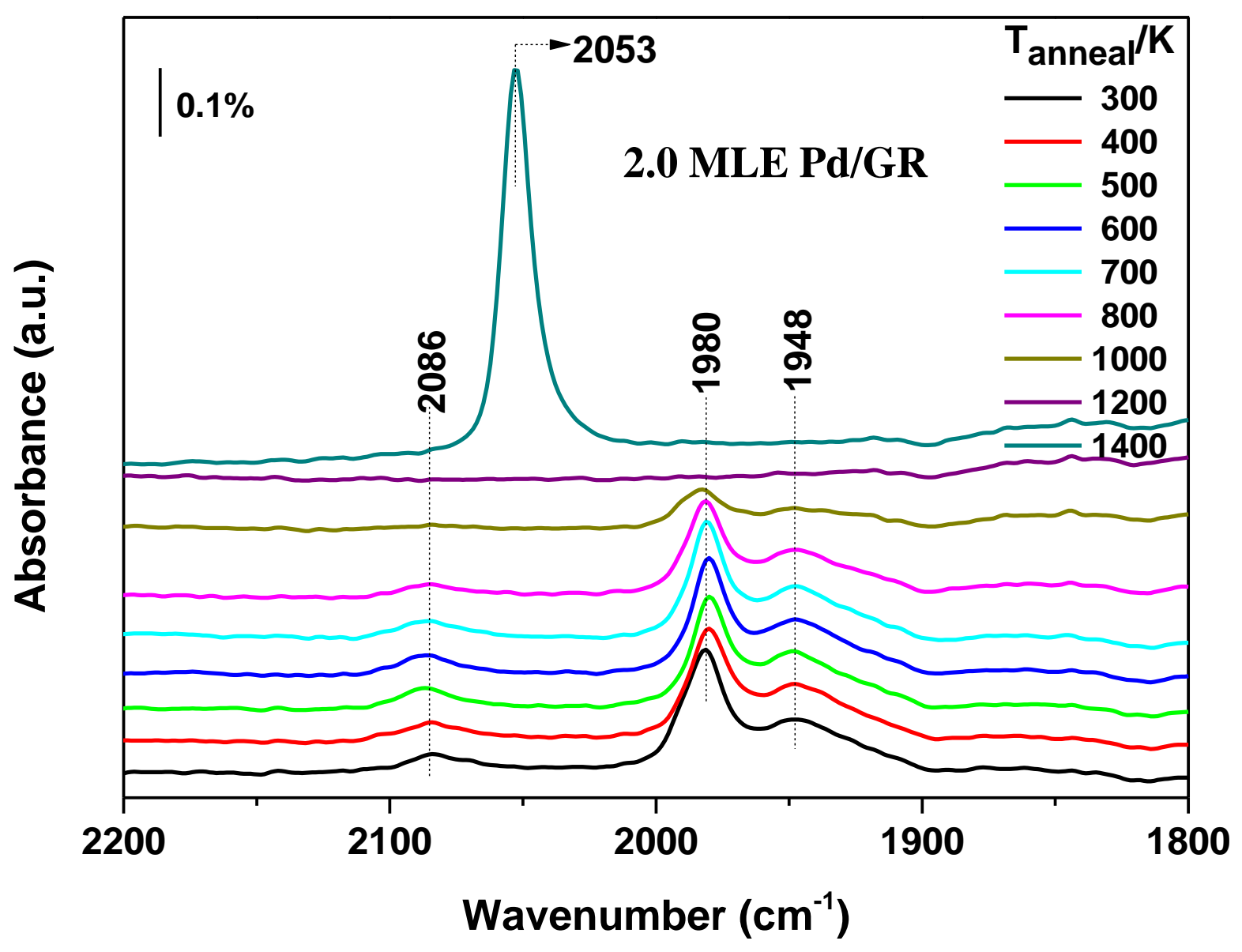

Figure 4 (b) Yi et.al 


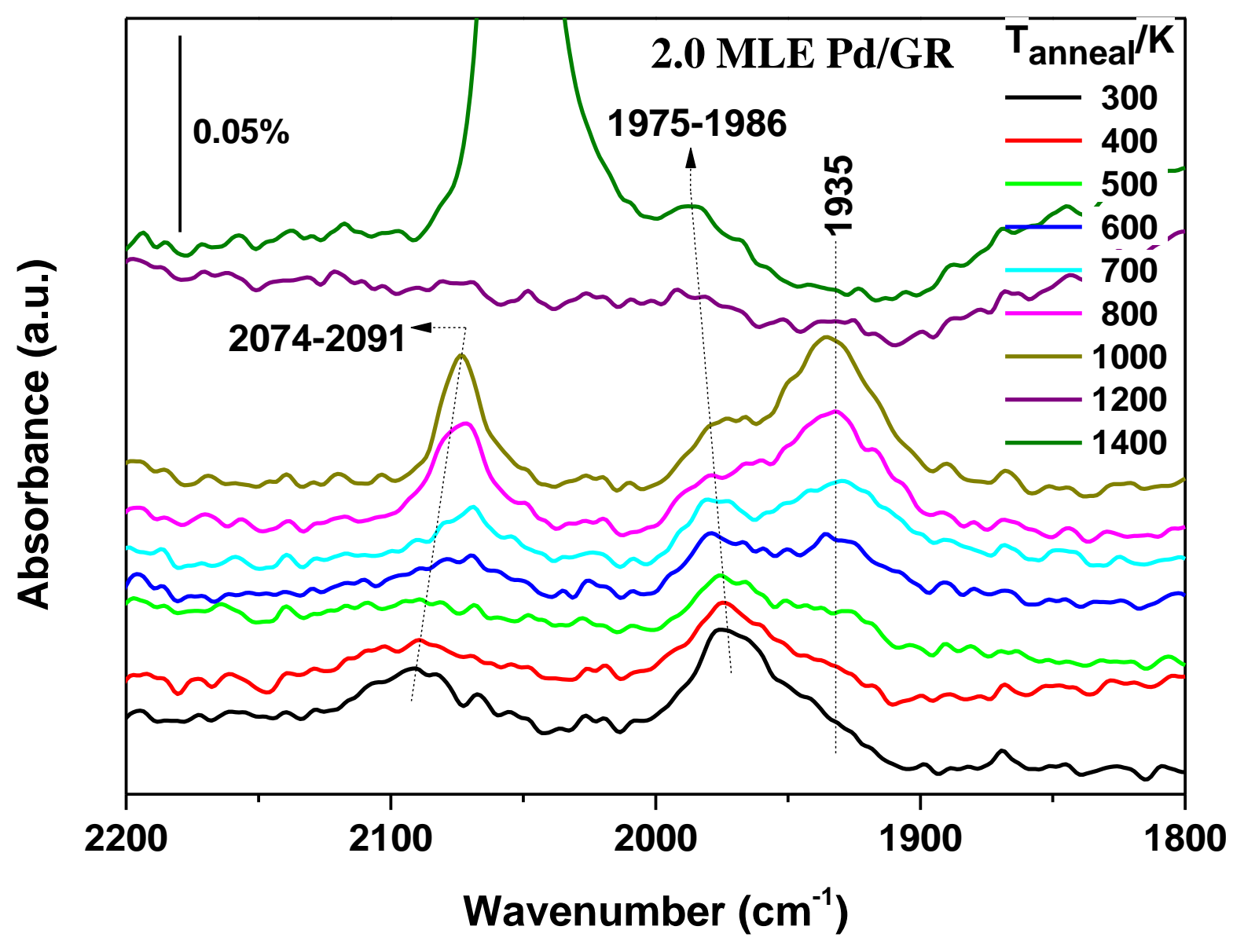

Figure 4 (c) Yi et al. 


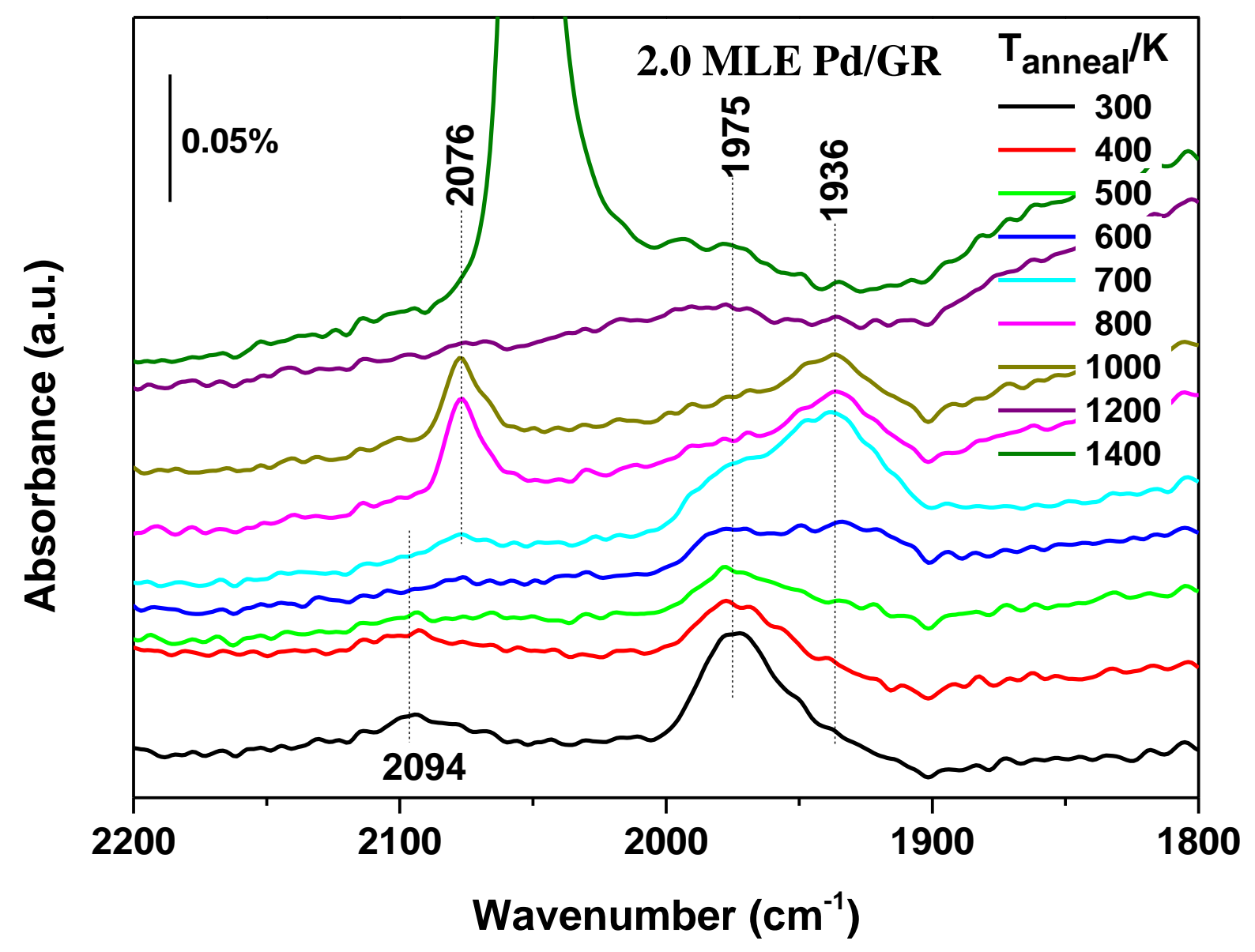

Figure 4 (d) Yi et al. 


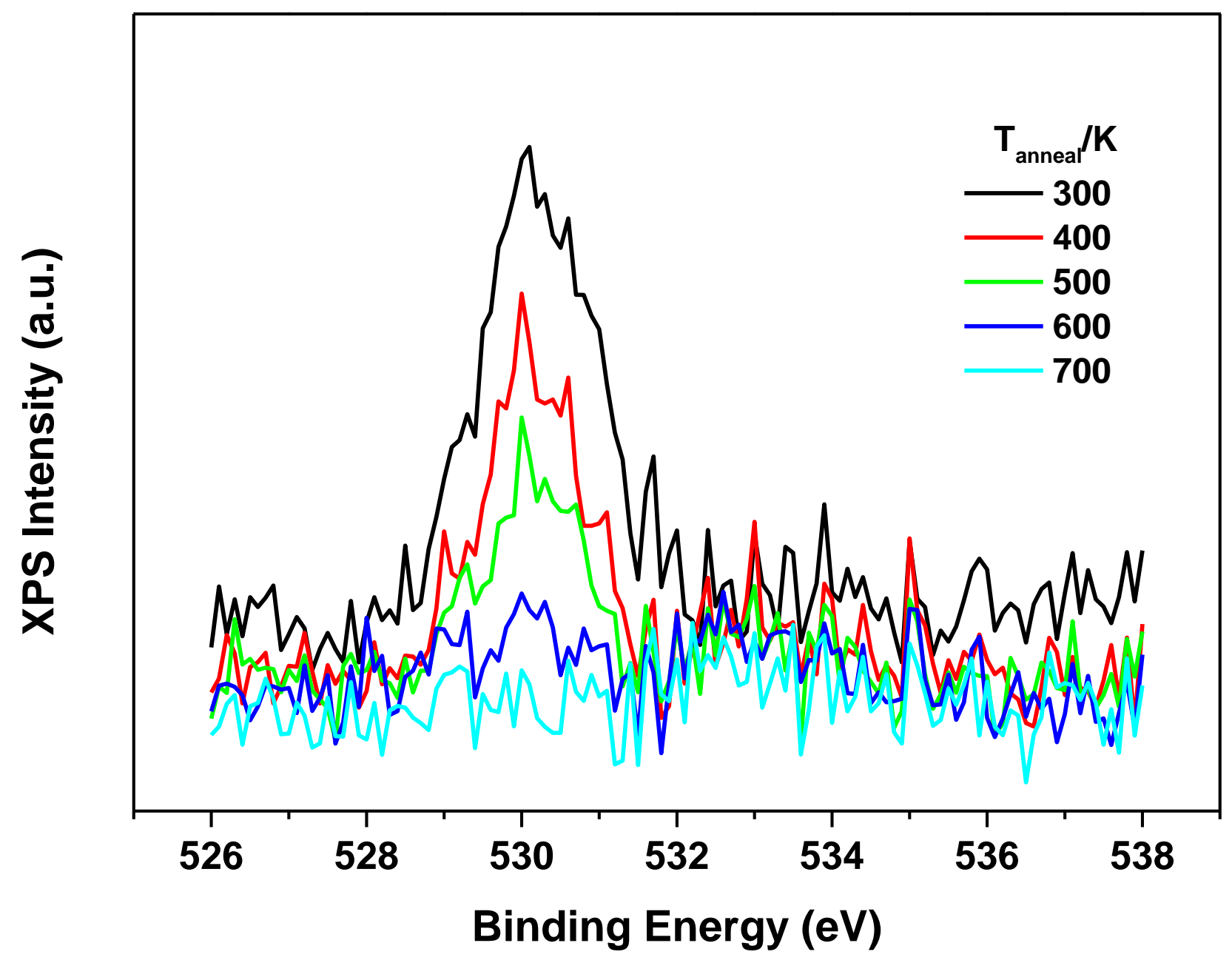

Figure S1 Yi et al. 